Research Article

\section{Patients' satisfaction and associated factors towards nursing care in Dessie Referral Hospital, Northeast Ethiopia}

\author{
Afework Edmealem ${ }^{1 *}$, Yabebal Asfaw ${ }^{1}$, Sewunet Ademe ${ }^{2}$ and \\ Belachew Tegegne ${ }^{1}$ \\ ${ }^{1}$ Lecturer, Department of Nursing, School of Nursing and Midwifery, Wollo University, Dessie, \\ Ethiopia \\ ${ }^{2}$ Department of Nursing, School of Nursing and Midwifery, Wollo University, Dessie, Ethiopia
}

\section{Abstract}

Introduction: A patient satisfaction is considered as one of the desire outcomes of health care and it is directly related with utilization of health services. However, its level is falls at the fundamental level in developing countries including Ethiopia.

Objective: To assess the level of patients' satisfaction and its associated factors at Dessie Referral Hospital, Northeast Ethiopia

Methods and Materials: An institutional based cross-sectional study design was employed from May 1 to June 1 2019. A total of 374 patients were selected by using systematic sampling technique and interviewer administer structured questionnaire was used to collect data. After data collection, the data were checked for its completeness and entered into Epi data version 3.1. The data were presented in frequency distribution tables and graphs. Both bivariable and multivariable logistic regression were applied to identify factors at a $p<0.05$

Result: Among total study participants, 220 (58.8\%) patients were satisfied with nursing care service. Patients who had particular nurse for nursing care were more likely satisfied than those who didn't have particular nurse for nursing care $(A O R=2.01,95 \% \mathrm{Cl}: 1.212-3.334)$. Patients who had other diseases in addition to current health problem were more likely satisfied (AOR $=0.45 \&$ $95 \% \mathrm{Cl}: 0.196-1.031)$ compared with patients who had not.

Conclusion: In this finding, the level of patients' satisfaction towards nursing care was low. Having specific or particular nurse and presence of comorbid disease were factors associated with patients' satisfaction towards nursing care. Health institutions should assign particular nurses for patients to improve their satisfaction and quality of care. In addition, nurses should give great attention to their patients who have co-morbid illnesses.

\section{More Information}

*Address for Correspondence: Afework Edmealem, Lecturer, Department of Nursing, School of Nursing and Midwifery, Wollo University, Dessie, Ethiopia, Tel: +2519 212872 07; Email: afeworkyalem@gmail.com

Submitted: 12 November 2019 Approved: 27 November 2019 Published: 29 November 2019

How to cite this article: Edmealem A, Asfaw Y, Ademe S, Tegegne B. Patient's satisfaction and associated factors towards nursing care in Dessie Referral Hospital, Northeast Ethiopia. Clin J Nurs Care Pract. 2019; 3: 053-058.

DOI: dx.doi.org/10.29328/journal.cjncp.1001018

Copyright: Edmealem A, et al. This is an open access article distributed under the Creative Commons Attribution License, which permits unrestricted use, distribution, and reproduction in any medium, provided the original work is properly cited.

Keywords: Patients; Nursing care; Patient satisfaction; Dessie referral hospital

(W) Check for updates

\section{Introduction}

Nurses are the professionals who provide holistic health care to patients as well as healthy individuals. This holistic care rendered by nurses' improves the lifestyle of individuals as well as their families and social communities. Nursing care encompasses autonomous and collaborative care of individuals of all ages, families, groups and communities, sick or well and in all settings. It includes the promotion of health, the prevention of illness, and the care of ill, disabled and dying people [1].

Patient satisfaction is a multidimensional concept which incorporates both medical and non-medical health care. It is the extent to which patients are happy with their healthcare, both inside and outside of the health facility. Patients' satisfaction gives providers insights into various aspects of medicine, including the effectiveness of their care and their level of empathy [2]. Measurement and understanding of the patient, caregiver, and family experience of healthcare provides the opportunity for reflection and improvement of health care and patient outcomes [3]. Patients' satisfaction is the main indicator of quality health care service. Since nurses give holistic care, patients' point of view to the nursing care is a good indicator of quality of nursing care. The level patients' satisfaction towards nursing care is widely varied across the world. Across the United States of America and Europe, patient satisfaction is playing an increasingly important role in quality of care reforms and health-care delivery [4].

There are different factors which are associated with patient satisfaction towards nursing care. One empirical 
analysis covers 31 countries reported that patient satisfaction is strongly associated with government health expenditure on the health care, the number of health care providers and the age of the patient [5]. Unsatisfied patients will not come back to the hospital, and it will lead to loss of income from the patient, as well as wastage of government resources. In Ethiopia, the nursing staffs and service given are improved time to time. However, the level of patients' satisfaction is not measured and assessed frequently. It is difficult to talk more about the quality of nursing care without assessing satisfaction level of patients. Thus, this study was initiated to assess the level of patients' satisfaction and associated factors towards nursing care in Dessie Referral Hospital, Northeast Ethiopia.

\section{Methods and Materials}

\section{Study area and period}

The study was conducted in Dessie Referral Hospital from May $1^{\text {st }}$ to June $1^{\text {st }} 2019$. It is located in Dessie town which is $401 \mathrm{~km}$ away from Addis Ababa. It has about 749 workers from this 548 are health professionals and 201 administrative staffs serving in hospital. Out of those health professionals, 332 were nurses and 61 of them are Diploma nurses with a total of 242 Beds.

\section{Study design}

An institutional based cross sectional study design was employed.

\section{Source of population}

All patients who were admitted in Dessie Referral Hospital were source population.

\section{Study population}

All admitted patients at Dessie Referral Hospital during the data collection period were study population.

\section{Inclusion and exclusion criteria}

\section{Inclusion criteria}

- Patients who were admitted greater than 24 hours

- Patients who are able to speak.

- Patients whose age is 18 and above

\section{Exclusion criteria}

- Patients who were severely ill, unconscious, unable to communicate

- Women in labor and

- Patients' whose age less than 18 years and did not have attendants were excluded from the study

\section{Sample size determination and sampling technique}

To determine the sample size for the study population the following assumption was made. The actual sample size for the study was determined using the formula single Population proportion by assuming 5\% degree of freedom and 95\% confidence interval at alpha $(\alpha=0.05)$ and the population proportion $(67 \%)$ were taken from a study conducted at Addis Ababa. So, based on the above information the total sample size were calculated by using the following formula. By taking the population proportion $p=67 \%$.

$$
\begin{aligned}
& \mathrm{Ni}=\frac{\left(\mathrm{Z}_{\alpha / 2}\right)^{2} \mathrm{p}(1-\mathrm{P})}{\mathrm{d}^{2}} \text { whereas } \mathrm{P}=\text { Estimate prevalence }=67 \\
& \mathrm{Ni}=\frac{(1.96)^{2} * 0.67(1-0.67)}{(0.05)^{2}}=340
\end{aligned}
$$

By adding 10\% non-response rate the total sample size was 374.

\section{Sampling technique}

The study was utilized systematic sampling technique. Initially, patients were allocated to medical, surgical, orthopedic, obstetrics and gynecology ward proportionally based on their admission in previous months. The previous month's patient flow was 762 per month. Finally, the study participants were selected in every $\mathrm{k}$ value which was 2 . K value was calculated as follows.

$\mathrm{K}$ value $=\mathrm{N} / \mathrm{n} ; \mathrm{N}=$ No of admitted patients admitted,

$\mathrm{n}=$ sample size $=762 / 374=2.03 \sim 2$

\section{Study variables}

\section{Dependent variable}

- Level of Patient satisfaction on nursing care

\section{Independent variable}

\section{Socio Demographic:}

- $\quad$ Sex

- $\quad$ Age

- Income

- Educational status

- Occupational status

- Language

- Religion

- Family monthly income

- $\quad$ Support

- Co morbid disease 


\section{Admission Characteristics:}

- $\quad$ Admission ward.

- $\quad$ Previous experience of admission

- $\quad$ Length of hospital stay

\section{Operational definitions of concepts}

Satisfied: Patients who got above the mean score of New castle Satisfaction with Nursing Scale.

Dissatisfied: Patients who got below the mean score of New castle Satisfaction with Nursing Scale.

\section{Data collection tools}

The data were collected using interviewer administered structured questionnaire by using standardized tool. It has different parts. The first part focuses Sociodemographic characteristics; the second part assesses patients' satisfaction towards nursing care with New castle Satisfaction with Nursing Scale. New castle Satisfaction with Nursing Scale is a standardize tool which used to assess patients' satisfaction towards nursing care throughout the world. All part of the questionnaire were prepared in English version initially and translated into Amharic then back to English to check their consistency.

\section{Data collection procedure}

After preparing the questionnaire, $6 \mathrm{BSc}$ nurses for data collection and $3 \mathrm{BSc}$ nurse for supervisor were recruited. Two days training were given for each of them on the meaning of every items of the questionnaire and the techniques of data collection such as ways of greeting, ways of taking consent, ways of data quality monitoring and ways of addressing ambiguous items. After this, data were collected by face to face interview at patients exit (during discharge time) by data collectors. To avoid repeated interview for patients with repeated visit during data collection period, data collectors asked and verified the patient whether interviewed or not before. In addition, study participants were informed about what nursing service mean and who nurses are before data collection. Supervisors and principal investigator monitored closely the data collection process.

\section{Data quality assurance}

The quality of data were assured by training data collectors and supervisors, carefully designing questionnaire, monitoring the data collection process and checking completeness of data during data collection time. In addition, pretest were conducted to address confusing items at Boru Meda Hospital.

\section{Data processing and analysis}

After data collection, completely collected data were entered in to epi data version 3.1 and exported to Statistical
Package and Service Product (SPSS) version 25 for analysis. Before analyzing the data, variables which have negative response were reversely coded. After that the three items of Likert scale (strongly disagree, disagree and neutral) were categorized as disagree and the rest two were categorized as agree. The results of study were presented by using text, tables and figures and binary logistic regression model was enrolled by considering 95\% confidence level and $p$ value of 0.05 . Multivariable binary logistic regression was done by taking variables that have $p$ value of $<0.25$ from bivariable logistic regression to identify factors associated with patients' satisfaction towards nursing care.

\section{Ethical consideration}

Before data collection period, ethical clearance and approval were obtained from Wollo University College of Medicine and Health Sciences Research and Ethical Committee. A supportive letter was given to the selected hospitals and permission was obtained from Hospital Manager to implement the study. Prior to interviewing the respondents, the aim and objectives of the study was clearly explained to the participants and oral informed consent was obtained. Additionally, participants were informed about the right to ask questions and stop response in anywhere. Confidentiality and anonymity were ensured throughout the execution of the study.

\section{Results}

\section{Socio-demographic characteristics of respondents}

A total of 374 participants were participated in the study with a response rate of $100 \%$. Among these, $260(61.5 \%)$ were females and the mean age of the participant was 37.7 ( $S D=11.96)$ with $141(37.7 \%)$ of the participants were in the age group of 18-30 years. The majority of the respondent 292 (78.1\%) were married, 217 (58\%) were Muslim in religion (Table 1).

\section{Patient and admission related characteristics}

Regarding the patient and admission related characteristics, majority of participant (40.9\%) were admitted at obstetrics and gynecology ward. Regarding the participants' history of admission, 261(69.8\%) of them had not history of previous admission, and 338 (90.4\%) of patient did not have other diseases other than current health problem. In addition, 300 (80.2\%) of the participants stayed for 2-10 night in their hospital, with the mean length of stays 1.28 (SD \pm 0.612 ) (Table 2).

\section{Level of patients' satisfaction towards nursing care}

According to the result, one fourth of the respondents were dissatisfied on the amount of time that the nurse spent with them. However, $315(84.2 \%)$ of the total respondents were satisfied to the freedom that a nurse give in the ward. In contrast to this, $104(27.8 \%)$ of the respondents were 
Table 1: Socio-demographic Characteristics of patients' in Dessie referral hospital Ethiopia, May $1^{\text {st }}-$ June $1^{\text {st }} 2019(\mathrm{~N}=374)$.

\begin{tabular}{|c|c|c|c|}
\hline \multicolumn{2}{|c|}{ Variable Category } & Frequency (N) & Percentage (\%) \\
\hline \multirow[t]{2}{*}{ Sex } & Male & 144 & 38.5 \\
\hline & Female & 260 & 61.5 \\
\hline \multirow{5}{*}{ Age } & $18-30$ yrs & 31 & 8.3 \\
\hline & $31-40$ yrs & 141 & 37.7 \\
\hline & $41-50$ yrs & 109 & 29.1 \\
\hline & $51-60$ yrs & 72 & 19.3 \\
\hline & $\geq 61 \mathrm{yrs}$ & 21 & 5.6 \\
\hline \multirow{4}{*}{ Marital status } & Single & 47 & 12.6 \\
\hline & Married & 292 & 78.1 \\
\hline & Widowed & 30 & 8.0 \\
\hline & Divorced & 5 & 1.3 \\
\hline \multirow{3}{*}{ Religion } & Muslim & 217 & 58.0 \\
\hline & Orthodox & 156 & 41.7 \\
\hline & Protestant & 1 & 3 \\
\hline \multirow{3}{*}{ Language } & Amhara & 367 & 98.1 \\
\hline & Oromo & 5 & 1.3 \\
\hline & Afar & 2 & 5 \\
\hline \multirow{6}{*}{$\begin{array}{c}\text { Educational } \\
\text { status }\end{array}$} & Unable to write and read & 73 & 19.5 \\
\hline & Grade 1 up to 8 & 106 & 28.3 \\
\hline & Grade 9 up to 12 & 94 & 25.1 \\
\hline & Certificate & 3 & 8 \\
\hline & Diploma & 49 & 13.1 \\
\hline & First degree $\&$ above & 49 & 13.1 \\
\hline \multirow{7}{*}{ Occupation } & Trader & 65 & 17.4 \\
\hline & Farmer & 73 & 19.5 \\
\hline & Civil servant & 90 & 24.1 \\
\hline & Student & 20 & 5.3 \\
\hline & Daily labour & 4 & 1.1 \\
\hline & House wife & 104 & 27.8 \\
\hline & Other & 18 & 4.8 \\
\hline \multirow{4}{*}{$\begin{array}{c}\text { Income: birr/ } \\
\text { month }\end{array}$} & $\leq 500$ birr & 10 & 3 \\
\hline & $501-1500$ birr & 60 & 16 \\
\hline & $1501-2500$ birr & 83 & 22 \\
\hline & $\geq 2501$ birr & 221 & 59 \\
\hline
\end{tabular}

Table 2: Patient and admission-related characteristics of the participants in Dessie Referral Hospital Ethiopia, May $1^{\text {st }}$ June $1^{\text {st }} 2019(n=374)$.

\begin{tabular}{|c|c|c|c|}
\hline \multicolumn{2}{|c|}{ Respondents' Characteristics } & $\begin{array}{l}\text { Frequency } \\
\text { (N) }\end{array}$ & $\begin{array}{c}\text { Percentage } \\
(\%)\end{array}$ \\
\hline \multirow{4}{*}{ Admission ward } & Medical ward & 80 & 21.4 \\
\hline & Orthopedics ward & 67 & 17.9 \\
\hline & Surgical ward & 74 & 19.8 \\
\hline & Obes/Gyne ward & 153 & 40.9 \\
\hline \multirow{3}{*}{ Length of hospital stay } & $2-10$ & 300 & 80.2 \\
\hline & $11-20$ & 42 & 11.2 \\
\hline & $>20$ & 32 & 8.6 \\
\hline \multirow{2}{*}{$\begin{array}{l}\text { History of previous } \\
\text { Admission }\end{array}$} & Yes & 113 & 30.2 \\
\hline & No & 261 & 69.8 \\
\hline \multirow{2}{*}{ Presence of co morbidities } & Yes & 36 & 9.6 \\
\hline & No & 338 & 90.4 \\
\hline \multirow{3}{*}{$\begin{array}{c}\text { Was particular nurse heir } \\
\text { to care you? }\end{array}$} & Yes & 132 & 35.3 \\
\hline & No & 120 & 32.1 \\
\hline & Not sure & 122 & 32.7 \\
\hline \multirow{2}{*}{$\begin{array}{c}\text { Over all how would you } \\
\text { rate you recent staying this } \\
\text { ward? }\end{array}$} & Not good & 192 & 51.3 \\
\hline & Good & 182 & 48.7 \\
\hline \multirow{5}{*}{ Who supports you? } & Parents & 32 & 8.6 \\
\hline & Self & 213 & 57.0 \\
\hline & husband/wife & 119 & 31.8 \\
\hline & brother/sister & 1 & .3 \\
\hline & Other & 9 & 2.4 \\
\hline
\end{tabular}

dissatisfied on the way the nurse made you feel at home. The overall level of patients' satisfaction is determined by considering the mean level of patients' satisfaction. In this study, $58.8 \%$ of the study participants were scored above the mean level satisfaction (Table 3).

\section{Factors associated patients' satisfaction towards nursing care}

Variables which have an association with patients' satisfaction towards nursing care at a $p$ value of $<0.25$ in bivariable logistic regression were marital status, monthly income, admission ward, support from others, assigned particular nurse and presence of co morbidities. These were entered into multivariable logistic regression to control potential confounding factors. However, in multivariable logistic regression, only assigned particular nurse and presence of co morbidities were associated with patients' satisfaction towards nursing care at $p$ value of $<0.05$. According to the result, patients who had a particular nurse were 2 times more likely satisfied with nursing care compared with patients who did not have particular nurse(AOR - 2.010; $95 \% \mathrm{CI}=1.212-3.334, p-0.007$ ) (Table 4).

\section{Discussion}

Patient satisfaction is the key indicator of quality nursing care. Although, there is improvement in quality of nursing care, still it falls at fundamental level in developing countries. Thus, this study was aiming to assess the level of patients' satisfaction towards nursing care. The overall proportion of patients who were satisfied with nursing care in this study was $58.8 \%$. This study is the same as conducted the study of Saminaet on nursing services large teaching hospital in India using prospectively study $57 \%$ is satisfied [6]. but percentage these study is lower compared to other studies in Jordan Patient's satisfaction revealed about (77\%) [7], study done northwest Ethiopia the overall satisfaction was found to be $67.1 \%$ [8]. The possible justification for this discrepancy might be the difference in socioeconomic status of the study areas.

However it is greater than a study in Study undergone in Ghana (33\%) [9] and Pakistan revealed 45\% [10] patients were satisfied with care provided. The discrepancy could be due to the difference in the tool, study period and Sociodemographic status. The findings of this study showed that there was no relationship between most of socio demographic variables including age, sex, educational status, occupation, ethnicity, patients overall satisfaction with nursing care. However, concerning marital status, this study showed that $63.3 \%$ married patient was satisfied than $44.7 \%$ of single patients. This is in agreement with finding in Turkey that married patients' satisfaction levels are higher than those of widows and divorced patients' [11]. This might be due to more than half of the patient was married and the social support and care that married patients receive from their spouses and children might decrease their care needs and expectation levels. 
Table 3: Level of patients' satisfaction towards nursing care in Dessie Referral Hospital Ethiopia, May $1^{\text {st }}-J^{\text {June }} 1^{\text {st }}, 2019(n=374)$

\begin{tabular}{|c|c|c|c|}
\hline \multirow{2}{*}{ S.No } & \multirow{2}{*}{ Items } & Satisfied & Dissatisfied \\
\hline & & $\mathrm{N}(\%)$ & $\mathrm{N}(\%)$ \\
\hline 1 & The amount of time nurse spent with you & $279(76.5)$ & $95(25.4)$ \\
\hline 2 & How capable nurse were at their job & $286(76.5)$ & $88(23.5)$ \\
\hline 3 & There always being a Nurse around if you need one. & $295(78.9)$ & $79(21.1)$ \\
\hline 4 & The amount nurse knew about your care & $287(76.7)$ & $87(23.3)$ \\
\hline 5 & The way the nurse made you feel at home & $270(72.2)$ & $104(27.8)$ \\
\hline 6 & The information nurse gave to you about your condition and treatment & $283(75.7)$ & $91(24.3)$ \\
\hline 7 & How often nurses checked to see if you were okay & $287(77.3)$ & $85(22.7)$ \\
\hline 8 & Nurses' helpfulness & $295(78.9)$ & $79(21.1)$ \\
\hline 9 & How nurses helped put your relatives' or friends' minds at rest & $282(75.4)$ & $92(24.6)$ \\
\hline 10 & Nurses' manner in going about their work & $302(80.7)$ & $72(19.3)$ \\
\hline 11 & The type of information nurses gave to you about your condition and treatment & $301(80.5)$ & $73(19.5)$ \\
\hline 12 & Nurse student' treatment of you as an individual & $296(79.1)$ & $78(20.9)$ \\
\hline 13 & How nurses listened to your worries and Concerns & $303(81)$ & $71(19)$ \\
\hline 14 & The amount of freedom you were given on the Ward & $315(84.2)$ & $59(15.8)$ \\
\hline 15 & How willing nurses were to respond to your Requests & $307(81.1)$ & $67(17.9)$ \\
\hline 16 & The amount of privacy nurses gave you & $306(81.8)$ & $68(18.2)$ \\
\hline 17 & Nurses' awareness of your needs & $304(81.3)$ & $70(18.7)$ \\
\hline
\end{tabular}

Table 4: logistic regression analysis of factors that affecting patients satisfaction with nursing care services in Dessie Referal hospital, Ethiopia, May $1^{\text {st }}-\mathrm{June}^{\text {st }}, 2019$ ( $\left.\mathrm{n}=374\right)$.

\begin{tabular}{|c|c|c|c|c|c|c|}
\hline \multirow{2}{*}{\multicolumn{2}{|c|}{ Variable }} & \multicolumn{5}{|c|}{ Patient satisfaction } \\
\hline & & \multirow{2}{*}{$\begin{array}{l}\text { Satisfied } \\
\qquad 21\end{array}$} & \multirow{2}{*}{$\begin{array}{c}\text { dissatisfied } \\
26\end{array}$} & \multirow{2}{*}{$\begin{array}{c}\operatorname{COR}(95 \% \mathrm{Cl}) \\
1.933(1.039-3.598)\end{array}$} & \multirow[t]{2}{*}{ AOR $(95 \% \mathrm{Cl})$} & \multirow[t]{2}{*}{$p$ value } \\
\hline \multirow{4}{*}{ Marital status } & Non married & & & & & \\
\hline & Windowed & 19 & 11 & $0.904(0.415-1.970)$ & & \\
\hline & Divorced & 2 & 3 & $2.342(0.385-14.234)$ & & \\
\hline & Married & 178 & 114 & 1 & & \\
\hline \multirow{4}{*}{ Income (In ETB } & $\leq 500$ birr & 21 & 26 & 1 & & \\
\hline & 501 - 1500 birr & 19 & 11 & $0.468(0.183-1.196)$ & & \\
\hline & 1501 - 2500 birr & 2 & 3 & $1.212(0.185-7.935)$ & & \\
\hline & $\geq 2501$ birr & 178 & 114 & $0.517(0.278-0.963)$ & & \\
\hline \multirow{4}{*}{ Admission ward } & Medical & 41 & 39 & 1 & & \\
\hline & Ortho ward & 40 & 27 & $0.710(0.368-1.368)$ & & \\
\hline & Surgical & 45 & 29 & $0.677(0.357-1.285)$ & & \\
\hline & Obs/gyni & 94 & 59 & $0.660(0.382-1.139)$ & & \\
\hline \multirow{4}{*}{ Supporter } & Self & 136 & 77 & $0.637(0.404-1.005)$ & & \\
\hline & Parents & 14 & 18 & $1.446(0.659-3.173)$ & & \\
\hline & Other & 7 & 3 & $0.563(0.134-2.355)$ & & \\
\hline & hasband/wife & 63 & 56 & 1 & & \\
\hline \multirow{3}{*}{$\begin{array}{l}\text { Assigned particular } \\
\text { nurse }\end{array}$} & Yes & 83 & 50 & $2.098(1.269-3.470)$ & $2.010(1.212-3.334)$ & 0.07 \\
\hline & No & 53 & 67 & 1 & 1 & \\
\hline & Not sure & 84 & 37 & $0.731(0.434-1.233)$ & $0.754(0.445-1.278)$ & 0.294 \\
\hline \multirow{2}{*}{ Presence of co orbid } & Yes & 28 & 8 & 1 & 1 & \\
\hline & No & 192 & 146 & $0.376(0.166-0.849)$ & $0.450(0.196-1.031)$ & 0.059 \\
\hline
\end{tabular}

This study revealed that patients who had a specific or particular nurse for nursing activity 2 times more likely to be satisfied than those who had no specific nurse for nursing activity. This might be because of nurse giving nursing care for a particular patient these increase patient and nurse relationship secondary to these reason increase satisfaction with nursing care (AOR $=2.01 ; 95 \% \mathrm{CI} 1.21$ - 3.33). Although it is not statically associated higher Income has been connected with greater satisfaction. People with lower income report more problems in hospital and reports dissatisfaction [10]. The findings of this study showed that $60.9 \%$ of patients who had $2500 \mathrm{birr} / \mathrm{month}$ and above income compared to $44.7 \%$ of patients who had $500 \mathrm{birr} / \mathrm{month}$ and below were satisfied. This might be because of more than half of our respondents had high monthly income ( $>2500$ birr).
In this study, patients' who did not had other diseases in addition to current health problem were less likely to be satisfied (AOR $=0.450 \& 95 \% \mathrm{CI}=0.196-1.031)$ than those who had. This is in line with study in Jordan revealed patients' with no other diseases tended to have higher satisfaction than those with other diseases [7]. This could be due to the fact that those patients' with other disease apart from the current health problem needs extra nursing care and follow up for that reason the nurse give that extra nursing care appropriately and follow frequently by those reason increase patient satisfaction. Patients' who have got freedom 315 $(84.2 \%)$, the amount of privacy nurses give you 306 (81.8\%) and nurse awareness of your needs 304 (81.3\%) were the aspects of nursing care services which were satisfied with the highest proportion of the study participants. However 
this was not in line with finding in Jordan patients had low levels of satisfaction with the amount of freedom in the ward, nurses' willingness to respond to requests, and in treating patients as individuals [12]. But this is in most cases congruent with previous studies $[13,14]$.

\section{Strength of the study}

Used well-structured questionnaire from validated survey instruments

Participation of patients' was also generally satisfactory with $100 \%$ response rate

Since interview was made with admitted patients; patients who stay for a long period of time were not missed.

\section{Limitation of the study}

Since the study was cross sectional, it shows only temporal relationship between variables (inability to infer causality).

> Patients' were not interviewed at sites away from the health facility. So, social desirability bias is also likely as the respondents were interviewed at their beds.

Satisfaction ratings were collected through face-toface interviews which might be subjected to response biases.

\section{Conclusion}

A little over half or $58.8 \%$ of the study participants were satisfied with the overall nursing care services; however, considerable proportions were not satisfied. On other hand, the freedom and privacy given to patients in the wards, nursing behavior and cooperation and responding quickly were important area of nursing care services with the highest satisfaction score. Having a particular nurse and having other diseases in addition to current health problem were found to be statistically associated with the patients' overall satisfaction towards nursing care.

\section{Recommendation}

- Health institution in particular health biro should give emphasis for regular in-service training program for nursing to refresh, up-to-date knowledge and skill on different aspects of patients care.

- Nursing school and college should work in collaboration with hospital for facilitating students' learning and achieving educational goals in turn beneficiary for patients' satisfaction.

- Nursing behavior and cooperation and responding quickly were important area of nursing care services with strongest quality of healthcare services that should be continued and encouraged more.
- Nurse's should aware and informed of extra care for those patient with co morbidity

- The future researcher should do an exit interview and qualitative study so as to minimize social desirability bias and to identify further factors

\section{Acknowledgment}

The researchers would also like to express heartfelt gratitude for all Dessie Referral Hospital staff members and the Dessie Referral Hospital office for their support and cooperative service provision. Finally, we also give our special thanks to patients who participated in this study for their willingness to share their experiences.

\section{References}

1. Advanced Practice in Nursing. Nursing Care. 2019.

2. Sara Heath. Patient Satisfaction and HCAHPS: What It Means for Providers. 2016.

3. Berkowitz B. The patient experience and patient satisfaction: measurement of a complex dynamic. Online J Issues Nurs. 2016; 1: 21. PubMed: https://www.ncbi.nlm.nih.gov/pubmed/27852212

4. Bleich SN, Murray CJ. How does satisfaction with the health-care system relate to patient experience?. Bulletin of the World Health Organization. 2009; 87: 271-278.

PubMed: https://www.ncbi.nlm.nih.gov/pubmed/19551235

5. Xesfingi S, Vozikis A. Patient satisfaction with the healthcare system: Assessing the impact of socio-economic and healthcare provision factors. BMC Health Services Res. 2016; 16: 94.

PubMed: https://www.ncbi.nlm.nih.gov/pubmed/26979458

6. Nyongesa MW, Onyango R, Kakai R. Determinants of clients' satisfaction with healthcare services at Pumwani Maternity hospital in Nairobi-Kenya. Int J Soc Behav Sci. 2014; 2: 11-17.

7. Ahmad MM, Alasad JA, Nawafleh $\mathrm{H}$. Nursing care and quality of life among Jordanian patients with cancer. Leadership in Health Services. 2010; 23: 233-243.

8. Negash AK, Negussie D, Demissie AF. Patients' satisfaction and associated factors with nursing care services in selected hospitals, Northwest Ethiopia. Am J Nurs Sci. 2014; 3: 34-42.

9. Rajeswari T. A study to assess patient's satisfaction with quality of nursing care. 2011.

10. Mohite NM, Shinde, Gulavani A. Job satisfaction among nurses working at selected tertiary care hospitals. Int J Sci Res. 2014; 3.

11. Özlü ZK, Uzun Ö, Evaluation of satisfaction with nursing care of patient's hospitalized in surgical clinics of different hospitals. Int $\mathrm{J}$ Caring Sci. 2015; 8: 19-24.

12. Molla M. Assessment of adult patient's satisfaction and associated factors with nursing care in Black Lion Hospital, Ethiopia; institutional based cross sectional study, 2012. Int J Nurs Midwifery. 2014; 6: 49-57.

13. Cheung C. Contributors to surgical in-patient satisfactiondevelopment and reliability of a targeted instrument. Asian J Surg. 2009; 32: 143-150.

PubMed: https://www.ncbi.nlm.nih.gov/pubmed/19656753

14. Sharma SK, Kamra PK. Patient satisfaction with nursing Care in Public and Private Hospitals. Nurs Midwifery Res J. 2013; 9: 130-141. 